\title{
Simulink Model of the Ares I Upper Stage Main Propulsion System*
}

\author{
Bradley T. Burchett ${ }^{\dagger}$ \\ Rose-Hulman Institute of Technology, Terre Haute, IN, 47803
}

\begin{abstract}
A numerical model of the Ares I upper stage main propulsion system is formulated based on first principles. Equations are written as non-linear ordinary differential equations. The GASP fortran code is used to compute thermophysical properties of the working fluids. Complicated algebraic constraints are numerically solved. The model is implemented in Simulink and provides a rudimentary simulation of the time history of important pressures and temperatures during re-pressurization, boost and upper stage firing. The model is validated against an existing reliable code, and typical results are shown.
\end{abstract}

\section{Nomenclature}

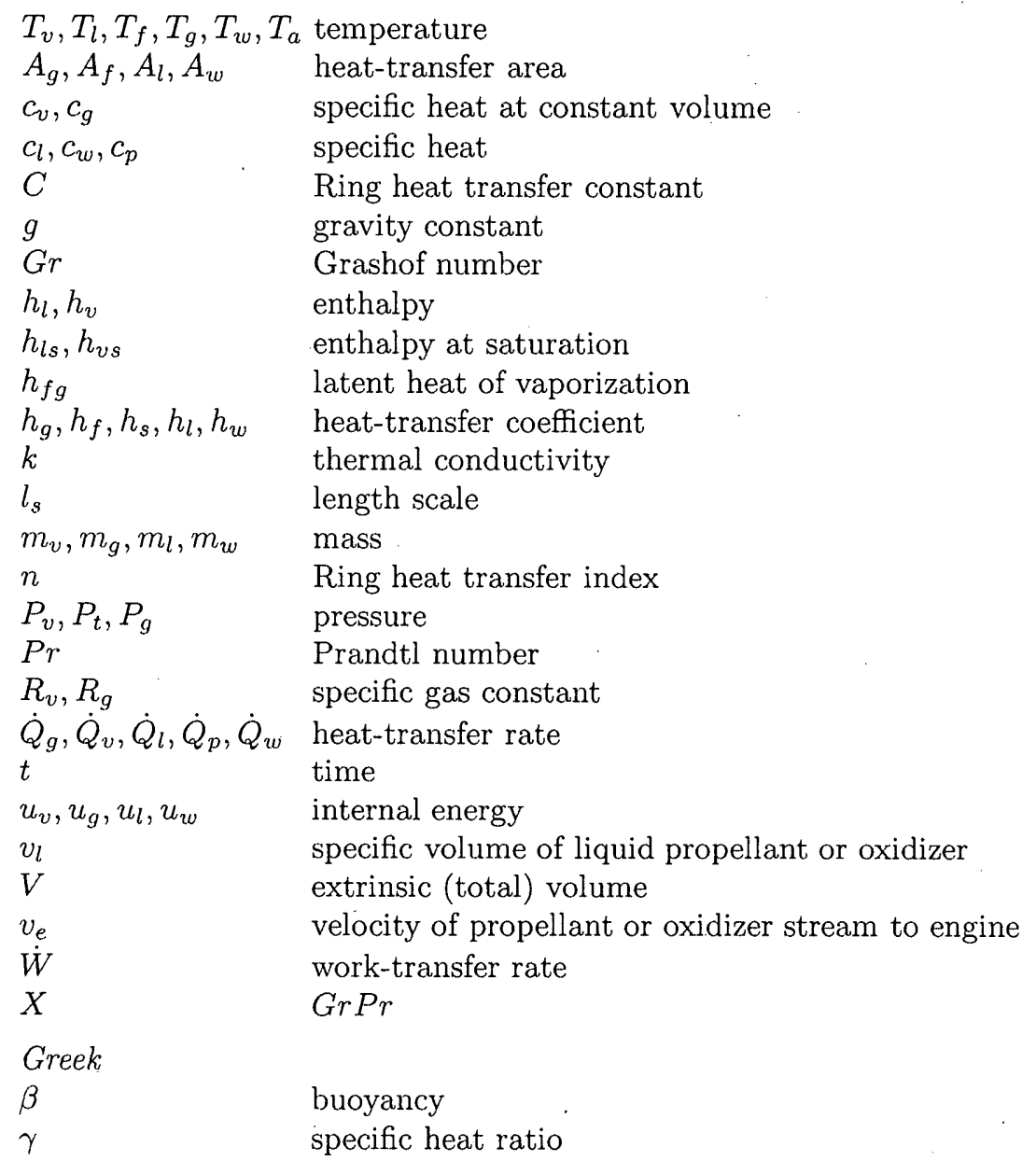

${ }^{*}$ This-work-was_supported by NASA/USRA contract númber NNM07AA02A_-In_compliance_with 22 CFR-Iñternational

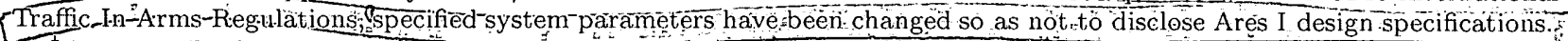

${ }^{\dagger}$ Associate Professor, Department of ${ }^{-M}{ }^{\prime}$ chanical ${ }^{-}$Engineering, burchett@rose-hulman.edu, Senior Member, AIAA 


$\begin{array}{ll}\mu & \text { viscosity } \\ \rho & \text { density }\end{array}$

\section{Subscript}

a

$e$

$f$

$g$

$i$

$l$

$\mathrm{O}_{2}$

$s$

$t$

$v$

$w$

$$
\begin{aligned}
& \text { ambient } \\
& \text { engine } \\
& \text { film layer } \\
& \text { pressure gas } \\
& \text { inlet } \\
& \text { propellant liquid } \\
& \text { interaction through common bulkhead } \\
& \text { wetted tank surface } \\
& \text { tank or total } \\
& \text { propellant or oxidizer vapor } \\
& \text { tank wall }
\end{aligned}
$$

Superscript

\section{Introduction}

$\mathrm{T}$ He fault detection, diagnosis and recovery laboratory (FDDR) at Marshall Space Flight Center will provide simulation of key subsystems of the Ares I launch vehicle and test innovative fault detection algorithms for possible employment on the vehicle: Since this development is proceeding in parallel with the actual vehicle design and construction, little or no actual test data exists. That is, actual time histories of pressures, temperatures, accelerations and other measurements do not yet exist. In order to provide a realistic simulation of the vehicle and environment, models based on physics must be developed. This work focuses on the Ares I upper stage main propulsion system (MPS).

In the past 50 years, many researchers have sought numerical models of pressurized propellant and oxidizer tanks. These models attempt to capture the heat and mass transfer behavior of the tank and working substance which for cryogenic fuels is multiphase due to boil off. As early as 1965, Roudebush obtained numerical solutions accounting for axial temperature distributions in the ullage gas and tank wall. ${ }^{1}$ Pasley $^{2}$ proposed an ODE model, with continuous ullage gas flow and demonstrated good comparison with hardware test data from the Surveyor spacecraft. Kendle ${ }^{3}$ compared experimental results with models assuming both mixed and stratified ullage volumes. Bush and associates ${ }^{4}$ derived models for both 'small' and 'large' ullage cases of a closed tank. For the small ullage case, the time history equations were reduced to a non-linear algebraic set. For the large ullage case, phase change complicated the problem and resulted in a set of 1-D PDEs.

More recently, several researchers have focused on modeling the X-34 MPS. ${ }^{5-9}$ X-34 uses RP-1 (kerosene) fuel and liquid Oxygen (LOX) oxidizer. Mcdonald et al ${ }^{5}$ performed CFD flow analysis of the X-34 MPS to detail fuel and oxidizer cg time history, tank bottom pressure history, and fuel/ullage stratification, a paramount constraint since the X-34 is launched in a horzontal attitude. Their results provide qualitative insight into the current solution. Majumdar and Steadman ${ }^{6}$ propose a finite volume numerical model including second law effects. They have developed a software tool called Generalized Fluid System Simulation Program (GFSSP) for network flow analysis. GFSSP has been validated against the Propulsion Test Article Helium Pressurization System ${ }^{7}$ at NASA Stennis, and the X-34 MPS. ${ }^{8}$ Thus it is considered a reliable simulation for the problem at hand and will be used to validate the models developed herein.

Here we capitalize on a model due to Estey et al. ${ }^{12}$ We are not concerned with spatial effects, hence the model is formulated by choosing a few control volumes, and treating each as a lumped element. In section II, we detail the system equations and correlations. Section III describes specifics about the Simulink implementation. Section IV presents the results of validation and nominal performance for boost and mainstage operation. 


\section{Development of the State Space Model}

The Ares I upper stage fuel and oxidizer tanks are depicted in Figure 1. Note that all relevant heat and mass transfer relationships are depicted, however, unique subscripts are not assigned for each tank, so the terms must be interpreted in their context (within each tank). The current design employs a common bulkhead between the Hydrogen and Oxygen tanks, and submerses the cryogenic Helium tanks in the $\mathrm{H}_{2}$ tank, thus requiring additional heat transfer interactions which are depicted. Each tank is divided into four control volumes, namely, the tank wall, ullage gas volume, film layer, and fuel/oxydizer liquid region. Temperature dynamics of the common bulkhead are not modeled-the bulkhead is simply treated as a thermal resistance.

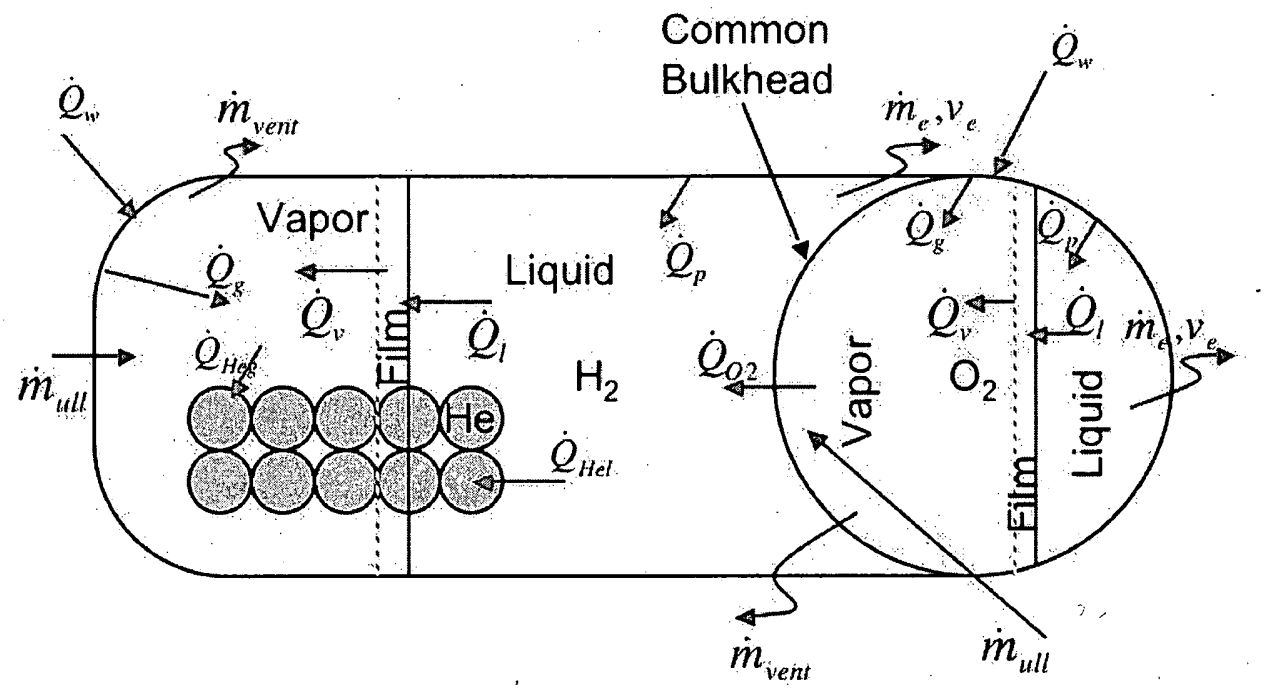

Figure 1. Arrangement of Ares I Upper Stage fuel and oxidizer tanks with heat and mass transfer interactions depicted.

\section{II.A. Liquid Oxygen Tank}

The Liquid Oxygen Tank is modeled first since it is pressurized in all modes with gaseous Helium. Estey ${ }^{12}$ provides a state space model for a single substance pressurized tank in blowdown mode. The Ares I MPS will use Helium pressurant in both liquid Oxygen and liquid Hydrogen tanks. Thus we must expand Estey's model to accomodate a gas/vapor mixture in the ullage space, and addition of ullage mass during tank re-pressurization and fuel expulsion. As shown in Figure 1, each tank is divided into four control volumes. The conservation of energy is then written for each control volume as follows. For the ullage space, the conservation of energy equation is

$$
\dot{Q}_{g}+\dot{Q}_{v}-\dot{Q}_{H_{2}}-\dot{W}+\dot{m}_{v} R_{v} T_{v}+\dot{m}_{g} R_{g} T_{g}=\left(m_{v} c_{v}+m_{g} c_{g}\right) \dot{T}_{v}
$$

The film layer is considered infinitessimally thin, and thus, we obtain the same equation as Estey ${ }^{12}$

$$
\dot{Q}_{l}-\dot{Q}_{v}+\dot{m}_{v} h_{l}-\dot{m}_{v} h_{v}=0
$$

The term $\dot{m}_{v}\left(h_{v}-h_{l}\right)$ can be rewritten as

$$
\dot{m}_{v}\left[\left(h_{v}-h_{v s}\right)-\left(h_{l}-h_{l s}\right)+\left(h_{v s}-h_{l s}\right)\right]=\dot{m}_{v}\left[\left(c_{v}+R_{v}\right)\left(T_{v}-T_{f}\right)-c_{l}\left(T_{l}-T_{f}\right)+h_{f g}\right]
$$


For the liquid region, the first law equation is unchanged from Estey ${ }^{12}$

$$
\dot{Q}_{p}-\dot{Q}_{l}+\dot{W}=\dot{m}_{e}\left(v_{e}^{2} / 2\right)+\ddot{m}_{l} c_{l} \dot{T}_{l}
$$

The tank wall conservation of energy equation is also unchanged from Estey ${ }^{12}$

$$
\dot{Q}_{w}-\dot{Q}_{p}-\dot{Q}_{g}=m_{w} c_{w} \dot{T}_{w}
$$

The heat transfer terms above are expanded as

$$
\begin{aligned}
\dot{Q}_{g} & =h_{g} A_{g}\left(T_{w}-T_{v}\right) \\
\dot{Q}_{v} & =h_{f} A_{f}\left(T_{f}-T_{v}\right) \\
\dot{Q}_{l} & =h_{s} A_{f}\left(T_{l}-T_{f}\right) \\
\dot{Q}_{p} & =h_{t} A_{s}\left(T_{w}-T_{l}\right) \\
\dot{Q}_{w} & =h_{w} A_{w}\left(T_{a}-T_{w}\right) \\
\dot{Q}_{O_{2}} & =h_{O_{2}} A_{O_{2}}\left(T_{v}-T_{H_{2}}\right) .
\end{aligned}
$$

The heat transfer coefficients $h_{g}$ and $h_{s}=h_{f}$ are determined from the natural convection correlation

$$
h_{i}=K_{H} C\left(k_{f} / l_{s}\right) X^{n}
$$

where

$$
\begin{aligned}
X & =(G r)(\operatorname{Pr}) \\
G r & =\left(l_{s}^{3} \rho_{f}^{2} g \beta_{f}|\Delta T| / \mu_{f}^{2}\right) \\
P r & =c_{p f} \mu_{f} / k_{f}
\end{aligned}
$$

$G r$ and $\mathrm{Pr}$ are the Grashof number and Prandtl number of the ullage gas, respectively. According to Ring, ${ }^{15}$ $C=0.27, n=0.25$, and $K_{H}=1$. The length scale $l_{s}$ is set to the diameter of the tank. The volumetric thermal expansion coefficient is defined as

$$
\beta_{f}=-\frac{1}{\rho_{f}}\left(\frac{\partial \rho_{f}}{\partial T}\right)_{p}
$$

and must typically be derived from finite differencing of $\rho$ wrt $T$. All thermophysical and transport properties required to compute $G r$ and $\mathrm{Pr}$ are found from ullage pressure and temperature using a Matlab executable (mex) of the Fortran based GASP code. ${ }^{16}$ In the $\mathrm{O}_{2}$ tank, the ullage gas is assumed to be a mixture of Oxygen and Helium, and the properties are computed by a weighted average of the pure substance properties based on mass ratios.

Substituting the heat transfer terms and Eqn 3 into Eqn 2, we obtain

$$
\dot{m}_{v}\left[\left(c_{v}+R_{v}\right)\left(T_{v}-T_{f}\right)-c_{l}\left(T_{l}-T_{f}\right)+h_{f g}\right]=h_{s} A_{f}\left(T_{l}-T_{f}\right)+h_{f} A_{f}\left(T_{f}-T_{v}\right)
$$

which can be solved independently for the rate of evaporation $\dot{m}_{v}$. Substituting the heat transfer terms into Eqn 5, we get

$$
m_{w} c_{w} \dot{T}_{w}=h_{w} A_{w}\left(T_{a}-T_{w}\right)-h_{t} A_{s}\left(T_{w}-T_{l}\right)-h_{g} A_{g}\left(T_{w}-T_{v}\right)
$$

which can be solved separately for the time rate of change of the wall temperature. The remaining equations are coupled during fuel expulsion due to the boundary work exerted by the ullage gas mixture on the liquid.

\section{II.A.1. Pressurization (Fuel Expulsion) Model}

Assuming a common temperature in the ullage space, and applying Dalton's law, the total ullage volume is

$$
V_{t o t}=\left(\frac{m_{v} R_{v}}{P_{v}}+\frac{m_{g} R_{g}}{P_{g}}\right) T_{v}
$$


The boundary work modeled as quasistatic work of expansion, $\dot{W}=P_{t}\left(d V_{g} / d t\right)$, where $P_{t}$ is the total ullage pressure. Differentiating $V_{\text {tot }}$ yields

$$
\frac{d V_{t o t}}{d t}=\left(\frac{\dot{m}_{v} R_{v}}{P_{v}}-\frac{m_{v} R_{v} \dot{P}_{v}}{P_{v}^{2}}+\frac{\dot{m}_{g} R_{g}}{P_{g}}-\frac{m_{g} R_{g} \dot{P}_{g}}{P_{g}^{2}}\right) T_{v}+\left(\frac{m_{v} R_{v}}{P_{v}}+\frac{m_{g} R_{g}}{P_{g}}\right) \dot{T}_{v} .
$$

Then

$$
\dot{W}=\left(P_{v}+P_{g}\right)\left[\left(\frac{m_{v} R_{v}}{P_{v}}+\frac{m_{g} R_{g}}{P_{g}}\right) \dot{T}_{v}+\left(\frac{\dot{m}_{v} R_{v}}{P_{v}}-\frac{m_{v} R_{v} \dot{P}_{v}}{P_{v}^{2}}+\frac{\dot{m}_{g} R_{g}}{P_{g}}-\frac{m_{g} R_{g} \ddot{P}_{g}}{P_{g}^{2}}\right) T_{v}\right]
$$

Substituting for the work term and the heat transfer terms in Eqn 1, we obtain

$$
\begin{aligned}
\left(m_{v} c_{v}+m_{g} c_{g}\right) \dot{T}_{v} & =\left(\dot{m}_{v} R_{v}+\dot{m}_{g} R_{g}\right) T_{v}+h_{g} A_{g}\left(T_{w}-T_{v}\right)-h_{O_{2}} A_{g}^{h}\left(T_{v}-T_{H_{2}}\right)+h_{f} A_{f}\left(T_{f}-T_{v}\right) \\
& -\left(P_{v}+P_{g}\right)\left[\left(\frac{m_{v} R_{v}}{P_{v}}+\frac{m_{g} R_{g}}{P_{g}}\right) \dot{T}_{v}+\left(\frac{\dot{m}_{v} R_{v}}{P_{v}}-\frac{m_{v} R_{v} \dot{P}_{v}}{P_{v}^{2}}+\frac{\dot{m}_{g} R_{g}}{P_{g}}-\frac{m_{g} R_{g} \dot{P}_{g}}{P_{g}^{2}}\right) T_{v}\right]
\end{aligned}
$$

Likewise, Eqn 4 becomes

$$
\begin{aligned}
\frac{1}{2} \dot{m}_{e} v_{e}^{2}+m_{l} c_{l} \dot{T}_{l} & =h_{t} A_{s}\left(T_{w}-T_{l}\right)-h_{s} A_{f}\left(T_{l}-T_{f}\right)-h_{O_{2} l} A_{l}^{h}\left(T_{l}-T_{H_{2}}\right) \\
& +\left(P_{v}+P_{g}\right)\left[\left(\frac{m_{v} R_{v}}{P_{v}}+\frac{m_{g} R_{g}}{P_{g}}\right) \dot{T}_{v}+\left(\frac{\dot{m}_{v} R_{v}}{P_{v}}-\frac{m_{v} R_{v} \dot{P}_{v}}{P_{v}^{2}}+\frac{\dot{m}_{g} R_{g}}{P_{g}}-\frac{m_{g} R_{g} \dot{P}_{g}}{P_{g}^{2}}\right) T_{v}\right]
\end{aligned}
$$

The tank total volume is invariant, thus given

$$
V_{t}=\frac{m_{v} R_{v} R_{v}}{P_{v}}+\frac{m_{g} R_{g} T_{v}}{P_{g}}+m_{l} v_{l}
$$

and differentiating, we obtain

$$
0=\frac{\dot{m}_{v n e t} R_{v} T_{v}}{P_{v}}+\frac{m_{v} R_{v} \dot{T}_{v}}{P_{v}}-\frac{m_{v} R_{v} T_{v} \dot{P}_{v}}{P_{v}^{2}}+\frac{\dot{m}_{g n e t} R_{g} T_{g}}{P_{g}}+\frac{m_{g} R_{g} \dot{T}_{v}}{P_{g}}-\frac{m_{g} R_{g} T_{v} \dot{P}_{g}}{P_{g}^{2}}
$$

Where $\dot{m}_{v n e t}$ and $\dot{m}_{\text {gnet }}$ include the sum of evaporation, venting and addition of ullage Oxygen vapor and Helium gas respectively. The system of equations is completed by enforcing an isothermal constraint in the ullage space.

$$
T_{g}=\frac{P_{g} V}{m_{g} R_{g}}=T_{v}=\frac{P_{v} V}{m_{v} R_{v}}
$$

Solving for $P_{g}$ and differentiating, we obtain

$$
\dot{P}_{g}=\dot{P}_{v} \frac{m_{g} R_{g}}{m_{v} R_{v}}+\frac{\dot{m}_{g} R_{g}}{m_{v} R_{v}}-\frac{m_{g} \dot{m}_{v} R_{g}}{m_{v}^{2} R_{v}}
$$

For ease of algebraic, or numeric solution, Eqns 17, 18, 20 and 22 are arranged into the matrix form

$$
\left[\begin{array}{cccc}
-G_{11} & G_{12} & 0 & -G_{14} \\
-G_{21} & G_{22} & 0 & -G_{24} \\
G_{31} & -G_{12} & G_{33} & G_{34} \\
G_{41} & 0 & 0 & -1
\end{array}\right]\left\{\begin{array}{c}
\dot{P}_{v} \\
\dot{T}_{v} \\
\dot{T}_{l} \\
\dot{P}_{g}
\end{array}\right\}=\left\{\begin{array}{c}
H_{1} \\
H_{2} \\
H_{3} \\
H_{4}
\end{array}\right\}
$$

Where

$$
\begin{aligned}
G_{11} & =\frac{m_{v} R_{v} T_{v}}{P_{v}^{2}} \\
G_{12} & =\frac{m_{v} R_{v}}{P_{v}}+\frac{m_{g} R_{g}}{P_{g}}
\end{aligned}
$$




$$
\begin{aligned}
G_{14} & =\frac{m_{g} R_{g} T_{v}}{P_{g}^{2}} \\
G_{21} & =-m_{v} R_{v} T_{v}\left(\frac{1}{P_{v}}+\frac{P_{g}}{P_{v}^{2}}\right) \\
G_{22} & =m_{v} c_{v}+m_{g} c_{g}+\left(P_{v}+P_{g}\right) G_{12} \\
G_{24} & =m_{g} R_{g} T_{v}\left(\frac{1}{P_{g}}+\frac{P_{v}}{P_{g}^{2}}\right) \\
G_{31} & =\left(P_{v}+P_{g}\right) G_{11} \\
G_{33} & =m_{l} c_{l} \\
G_{34} & =\left(P_{v}+P_{g}\right) G_{14} \\
G_{41} & =\frac{m_{g} R_{g}}{m_{v} R_{v}}
\end{aligned}
$$

and

$$
\begin{aligned}
& H_{1}=-\frac{\dot{m}_{g} R_{g} T_{g}}{P_{g}}-\frac{\dot{m}_{v} R_{v} T_{v}}{P_{v}}+\dot{m}_{e} v_{l}+v_{l} \dot{m}_{v} \\
& H_{2}=h_{g} A_{g}\left(T_{w}-T_{v}\right)-h_{O_{2}} A_{g}^{h}\left(T_{v}-T_{H_{2}}\right)+h_{f} A_{f}\left(T_{f}-T_{v}\right)-\frac{P_{g} R_{v}}{P_{v}} \dot{m}_{v}-\frac{P_{v} R_{g}}{P_{g}} \dot{m}_{g} \\
& H_{3}=h_{t} A_{s}\left(T_{w}-T_{l}\right)-h_{s} A_{f}\left(T_{l}-T_{f}\right)-h_{O_{2}} A_{l}^{h}\left(T_{l}-T_{H_{2}}\right)+\left(P_{v}+P_{g}\right)\left(\frac{\dot{m}_{v} R_{v}}{P_{v}}+\frac{\dot{m}_{g} R_{g}}{P_{g}}\right) T_{v}-\frac{1}{2} \dot{m}_{e} v_{e}^{2} \\
& H_{4}=-\frac{\dot{m}_{g} R_{g}}{m_{v} R_{v}}+\frac{m_{g} \dot{m}_{v} R_{g}}{m_{v}^{2} R_{v}}
\end{aligned}
$$

An algebraic solution of Eqn 23 is possible, but cumbersome, so we rely on a numeric solution for the state derivatives in Eqn 23.

\section{II.A.2. Re-Pressurization and Re-circulation Model}

During ground operations, and first stage boost, the liquid fuel mass inside the tank is essentially constant, and the boundary work term may be neglected. This modifies the previous equations in that terms $G_{21}, G_{24}, G_{31}, G_{12}$, and $G_{34}$ are zero. Thus the equations for $\dot{T}_{v}$ and $\dot{T}_{l}$ may be solved directly as follows.

$$
\begin{gathered}
\dot{T}_{v}=\frac{1}{m_{v} c_{v}+m_{g} c_{g}}\left[h_{g} A_{g}\left(T_{w}-T_{v}\right)-h_{O_{2}} A_{g}^{h}\left(T_{v}-T_{H_{2}}\right)+h_{f} A_{f}\left(T_{f}-T_{v}\right)+\left(\dot{m}_{v n e t} R_{v}+\dot{m}_{g n e t} R_{g}\right) T_{v}\right] \\
\dot{T}_{l}=\frac{1}{m_{l} c_{l}}\left[h_{t} A_{s}\left(T_{w}-T_{l}\right)-h_{s} A_{f}\left(T_{l}-T_{f}\right)-h_{O_{2}} A_{l}^{h}\left(T_{l}-T_{H_{2}}\right)-\dot{m}_{l} c_{l}\left(T_{l}-T_{l i}\right)\right]
\end{gathered}
$$

Where $\dot{m}_{l}$ and $T_{l i}$ are respectively the mass flow rate and return temperature of the recirculation loop. The equations for $\dot{P}_{g}$ and $\dot{P}_{v}$ remain coupled and can be written as the linear system

$$
\left[\begin{array}{cc}
1 & -G_{41} \\
G_{14} & G_{11}
\end{array}\right]\left\{\begin{array}{l}
\dot{P}_{g} \\
\dot{P}_{v}
\end{array}\right\}=\left\{\begin{array}{l}
\frac{\dot{m}_{g n e t} R_{g}}{m_{v} R_{v}}-\frac{m_{g} \dot{m}_{v n e t} R_{g}}{m_{v}^{2} R_{v}} \\
\frac{\dot{m}_{v} R_{v} R_{v} T_{v}}{P_{v}}+\frac{m_{v} R_{v} \dot{T}_{v}}{P_{v}}-\dot{m}_{l} v_{l}+\frac{\dot{m}_{g n e t} R_{g} T_{g}}{P_{g}}+\frac{m_{g} R_{g} \dot{T}_{v}}{P_{g}}
\end{array}\right\}
$$

\section{II.B. Liquid Hydrogen Tank}

The Liquid Hydrogen Tank is somewhat more complicated since its ullage gas is Helium for re-pressurization, and Hydrogen during engine firing. It is also more complicated due to heat transfer interaction with the cryogenic Helium tanks which are submersed in the liquid Hydrogen tank.

\section{II.B.1. Pressurization (Fuel Expulsion) Model}

During fuel expulsion, gaseous Hydrogen is added to maintain ullage pressure. The ullage gas will contain some He from re-pressurization, however we consider the He mass to be negligible in light of the rapidly growing Hydrogen vapor mass. The energy balance equation for the ullage volume is

$$
\dot{Q}_{g}+\dot{Q}_{v}-\dot{Q}_{H e g}-\dot{W}=m_{v} c_{v} \dot{T}_{v}-\dot{m}_{v} R_{v} T_{v}-\dot{m}_{u l l} R_{v} T_{v}
$$


The boundary work term for a single species ullage is

$$
\dot{W}=\frac{1}{P_{v}}\left(\left(\dot{m}_{v} T_{v}+m_{v} \dot{T}_{v}\right) P_{v}-m_{v} T_{v} \dot{P}_{v}\right) R_{v}
$$

where $\dot{m}_{v}$ and $\dot{m}_{u l l}$ are vapor mass added by evaporation, and ullage pressure regulation respectively. Thus substituting the heat transfer terms and boundary work, Eqn 3b becomes

$$
\begin{aligned}
m_{v} c_{v} \dot{T}_{v}-\left(\dot{m}_{v}+\dot{m}_{u l l}\right) R_{v} T_{v} & =h_{g} A_{g}\left(T_{w}-T_{v}\right)+h_{f} A_{f}\left(T_{f}-T_{v}\right)-h_{H e g} A_{H e g}\left(T_{v}-T_{H e}\right) \\
& -\frac{1}{P_{v}}\left(\left(\dot{m}_{v} T_{v}+m_{v} \dot{T}_{v}\right) P_{v}-m_{v} T_{v} \dot{P}_{v}\right) R_{v}
\end{aligned}
$$

The film layer dynamics are identical to those of the Oxygen tank. The liquid Hydrogen control volume differs from that of Oxygen because of the single species work term, and the extra heat transfer term due to interaction with the cryogenic He tanks.

$$
\dot{Q}_{p}+\dot{Q}_{H_{2}}-\dot{Q}_{l}-\dot{Q}_{H e l}+\dot{W}=\dot{m}_{e} \frac{v_{e}^{2}}{2}+m_{l} c_{l} \dot{T}_{l}
$$

Which after the appropriate substitutions becomes

$$
\begin{aligned}
\dot{m}_{e} \frac{v_{e}^{2}}{2}+m_{l} c_{l} \dot{T}_{l} & =h_{t} A_{s}\left(T_{v}-T_{l}\right)+h_{H_{2}} A_{H_{2}}\left(T_{O_{2}}-T_{l}\right)-h_{s} A_{f}\left(T_{l}-T_{f}\right)-h_{H e l} A_{H e l}\left(T_{l}-T_{H e}\right) \\
& +\frac{1}{P_{v}}\left(\left(\dot{m}_{v} T_{v}+m_{v} \dot{T}_{v}\right) P_{v}-m_{v} T_{v} \dot{P}_{v}\right) R_{v}
\end{aligned}
$$

Note that subscripts in these equations must be interpreted in their context, i.e. $T_{l}$ immediately above refers to the temperature of liquid Hydrogen, wheras in subsection II.A., it refers to the temperature of liquid Oxygen. The tank wall energy equation is identical to Eqn 13. The total volume equation for a single species ullage is $V_{t}=m_{v} R_{v} T_{v} / P_{v}+m_{l} v_{l}$ which when differentiated yields

$$
0=\frac{\dot{m}_{v} R_{v} T_{v}}{P_{v}}+\frac{m_{v} R_{v} \dot{T}_{v}}{P_{v}}-\frac{m_{v} R_{v} T_{v} \dot{P}_{v}}{P_{v}^{2}}-\dot{m}_{v} v_{l}-\dot{m}_{e} v_{l}+\dot{m}_{u l l} \frac{R_{v} T_{v}}{P_{v}}
$$

To facilitate solution of the state derivatives, Eqns 43, 45 and 46 are arranged in the matrix form

$$
\left[\begin{array}{ccc}
-\frac{m_{v} R_{v} T_{v}}{P_{v}^{2}} & \frac{m_{v} R_{v}}{P_{v}} & 0 \\
\frac{m_{v} R_{v} T_{v}}{P_{v}} & -m_{v} c_{v}-m_{v} R_{v} & 0 \\
-\frac{m_{v} R_{v} T_{v}}{P_{v}} & m_{v} R_{v} & -m_{l} c_{l}
\end{array}\right]\left\{\begin{array}{c}
\dot{P}_{v} \\
\dot{T}_{v} \\
\dot{T}_{l}
\end{array}\right\}=\left\{\begin{array}{c}
H_{1} \\
H_{2} \\
H_{3}
\end{array}\right\}
$$

where

$$
\begin{aligned}
& H_{1}=-\frac{\dot{m}_{v} R_{v} T_{v}}{P_{v}}+\dot{m}_{v} v_{l}+\dot{m}_{e} v_{l}-\dot{m}_{u l l} \frac{R_{v} T_{v}}{P_{v}} \\
& H_{2}=\dot{m}_{v} T_{v} R_{v}-\left(\dot{m}_{v}+\dot{m}_{u l l}\right) R_{v} T_{v}-h_{g} A_{g}\left(T_{w}-T_{v}\right)-h_{f} A_{f}\left(T_{f}-T_{v}\right)+h_{H e g} A_{H e g}\left(T_{v}-T_{H e}\right) \\
& H_{3}=\dot{m}_{e} \frac{v_{e}^{2}}{2}-\dot{m}_{v} T_{v} R_{v}-h_{t} A_{s}\left(T_{w}-T_{l}\right)-h_{H_{2}} A_{H_{2}}\left(T_{O_{2}}-T_{l}\right)+h_{s} A_{f}\left(T_{l}-T_{f}\right)+h_{H e l} A_{H e l}\left(T_{l}-T_{H e}\right)(50
\end{aligned}
$$

Clearly the LHS of Eqn 47 is a Hessenberg permutation, so the equations for $\dot{P}_{v}$ and $\dot{T}_{v}$ can be solved independently of $\dot{T}_{l}$. Also due to this structure, the equations can be algebraically solved relatively easily yielding

$$
\left\{\begin{array}{c}
\dot{P}_{u} \\
\dot{T}_{v} \\
\dot{T}_{l}
\end{array}\right\}=\left[\begin{array}{ccc}
-\frac{\left(c_{v}+R_{v}\right) P_{v}^{2}}{m_{v} T_{v} R_{v} c_{v}} & -\frac{P_{v}}{m_{v} T_{v} c_{v}} & 0 \\
-\frac{P_{v}}{m_{v} c_{v}} & -\frac{1}{m_{v} c_{v}} & 0 \\
\frac{P_{v}}{m_{l} c_{l}} & 0 & -\frac{1}{m_{l} c_{l}}
\end{array}\right]\left\{\begin{array}{c}
H_{1} \\
H_{2} \\
H_{3}
\end{array}\right\}
$$




\section{II.C. Pressurant Subsystems}

Prior to launch, the cryogenic He bottles are pressurized to $3277 \mathrm{psi}$ or $22.59 \mathrm{MPa}$, which is a supercritical pressure. The ten bottles have a total volume of $1.00 \mathrm{~m}^{3}$. The initial stored He mass equals $200 \mathrm{~kg}$, which is based on the assumption that the cryogenic He initial temperature is equal to that of the liquid $\mathrm{H}_{2}(20 \mathrm{~K})$. Prior to injection in the fuel and $\mathrm{O}_{2}$ tanks, the He passes through a regulator which reduces its pressure to $435 \mathrm{psi}$ or $3.0 \mathrm{MPa}$. We simulate the pressurization control as a simple relay with on/off thresholds set to 35 and 40 psi respectively for the $\mathrm{H}_{2}$ tank and 25 and 30 psi for the $\mathrm{O}_{2}$ tank.

In order to determine the mass flow rate of ullage gas into the tank when the control valve is open, we use the relationships from Palm. ${ }^{13}$ The critical pressure for an ideal gas is

$$
P_{c}=\left(\frac{2}{\gamma+1}\right)^{\gamma /(\gamma-1)} P_{1}
$$

where $P_{1}$ is the supply pressure. For typical gases, the critical pressure tends to be about $1 / 2$ of the supply pressure or higher. Since the tank pressure is around 1/10 to $1 / 20$ of the supply pressure in this case, we consider the flow into the tank to be sonic, and use the following relationship for mass flow rate

$$
\dot{m}_{u l l}=C_{d} A \frac{P_{1}}{\sqrt{R_{g} T_{1}}} \sqrt{\gamma\left(\frac{2}{\gamma+1}\right)^{(\gamma+1) /(\gamma-1)}} .
$$

Where $A$ is the orifice area, $T_{1}$ is the supply temperature, and $C_{d}$ is a discharge coefficient which is assumed to be unity.

Knowing the net mass flow rate out of the cryo $\mathrm{He}$ tanks and into the fuel and $\mathrm{O}_{2}$ tanks, we predict the time history of mass in the cryo He tank simply by integrating. The cryo He pressure history is then calculated by $\mathrm{GASP}^{16}$ from current density assuming temperature equals $20 \mathrm{~K}$.

\section{II.D. Thermophysical Properties}

The film temperature is assumed to be the working fluid saturation temperature at current tank pressure. These are calculated from saturation pressure by numerical solution of the equation

$$
\log _{10} P_{s a t}=j_{1}+\frac{j_{2}}{T}+j_{3} T+j_{4} T^{2}+j_{5} T^{3}+j_{6} T^{4}+j_{7} T^{5}
$$

where the $j$ coefficients for Hydrogen and Oxygen are shown in Table 1. Since the equation above is a polynomial in the unknown $T$, a first-order newton method is used, applying the analytic gradient. Solution is facilitated by a small set of subroutines from GASP $^{16}$ which have been mex-ed for use with Simulink.

Table 1. Coefficients used to compute saturation temperature from pressure

\begin{tabular}{cccccccc}
\hline \hline Substance & $j_{1} / 10^{1}$ & $j_{2} / 10^{2}$ & $j_{3}$ & $j_{4} / 10^{-2}$ & $j_{5} / 10^{-4}$ & $j_{6} / 10^{-6}$ & $j_{7} / 10^{-9}$ \\
\hline Hydrogen & -0.1059 & -0.3525 & 0.3787 & -2.360 & 8.553 & -16.18 & 125.0 \\
Oxygen & -0.5150 & -2.563 & 0.2628 & -0.3622 & 0.2652 & -0.1000 & 0.1542 \\
\hline \hline
\end{tabular}

For cryogenic He, supply pressure is computed from temperature and density. Figure 2 on the next pagea compares the GASP pressure values at $20 \mathrm{~K}$ with data from the National Institute of Standards (NIST) chemistry web-book. ${ }^{17}$ Figure 2 on the following pageb shows the time history of cryogenic He pressure during boost and upper stage firing.

\section{II.D.1. Volume and wetted area}

A sphere of radius $r$ filled to a height $h$ contains a volume equal to

$$
V=\pi r h^{2}-\pi \frac{h^{3}}{3}
$$

The fluid covers a 'wetted area' equal to $A=2 \pi r h$. Solving for fluid height as a function of volume is algebraically cumbersome, so instead, we solve Eqn 55 numerically using a Newton method. 


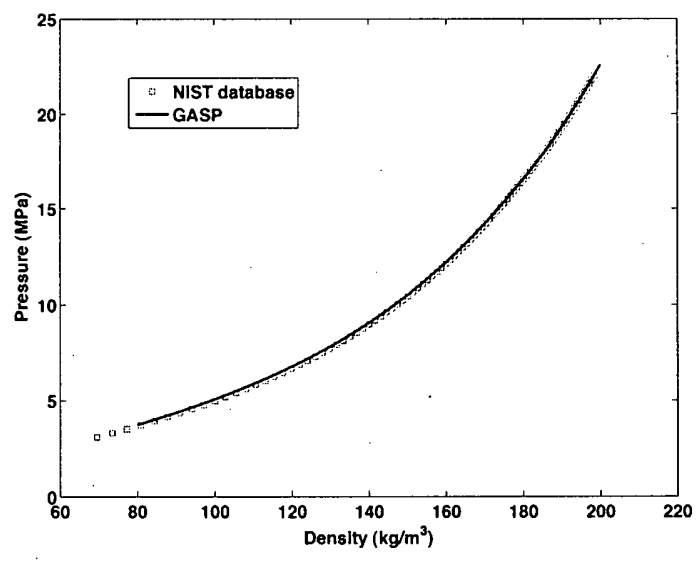

(a) GASP pressure from density

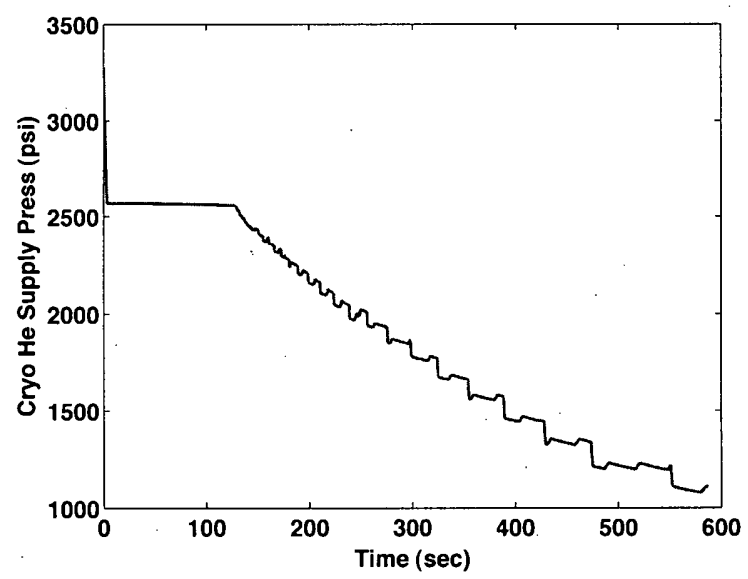

(b) Pressure time history

Figure 2. Cryogenic Helium Sample Results

\section{Simulink Implementation}

The equations above were implemented in a Simulink model. Due to its size the overall block diagram is shown in the Appendix. The system decomposition in Simulink is by function rather than form. An attempt was made to decompose by form (physical components) but this resulted in algebraic loops. In this section we will tour the model block by block explaining similarities and differences.

\section{III.A. Tank Models}

The state derivatives in Eqns 23, 40, and 47 are numerically solved and integrated in the 'LH2' and 'LO2' blocks which are expanded below. The Matlab function blocks 'H2tank' and 'O2tank' provide solutions for the state derivatives, and include logic to choose between Eqn 23 (fuel explusion mode) and Eqn 40 (recirculation mode). The current 'H2tank' implementation uses Eqns 23 and 40 to account for a mixture of $\mathrm{H}_{2}$ vapor and $\mathrm{He}$ gas"in the ullage.

\section{III.B. Ullage regulators}

Ullage gas injection is modeled using a relay and the compressible flow relationship from Eqn 53. The relay is set to $\pm 2.5 \mathrm{psi}$ of the specified ullage pressure. The Matlab function block 'GHe1' implements Eqn 53 with He properties. The He regulator blocks use an external constant for supply pressure since the supply pressure for $\mathrm{H}_{2}$ Helium injection is $435 \mathrm{psi}\left(3.0 \mathrm{MPa}\right.$ ) while the supply pressure for $\mathrm{O}_{2} \mathrm{He}$ injection is $363 \mathrm{psi}$ $(2.5 \mathrm{MPa})$. The regulators for $\mathrm{H}_{2}$ also include switching logic to select $\mathrm{He}$ injection for recirculation mode and gaseous $\mathrm{H}_{2}$ injection for fuel expulsion mode.

\section{III.C. Relief Vents}

The $\mathrm{H}_{2}$ tank vent relay is set to open at $49 \mathrm{psi}(337.9 \mathrm{kPa})$ and close at $40 \mathrm{psi}(275.8 \mathrm{kPa})$. Flow through the vent is determined using Eqn 53 where the gas properties are found by a weighted average of $\mathrm{H}_{2}$ vapor and $\mathrm{He}$ gas properties according to the respective masses in the ullage. The $\mathrm{O}_{2}$ tank vent relay is set to open at $49 \mathrm{psi}(337.9 \mathrm{kPa})$, and close at $30 \mathrm{psi}(206.8 \mathrm{kPa})$. The flow through both vents is assumed to be sonic which is a valid assumption except in the case that the $\mathrm{O}_{2}$ tank pressure is below $30.1 \mathrm{psi}(207.5 \mathrm{kPa})$, while the ambient pressure is standard sea-level or higher. 


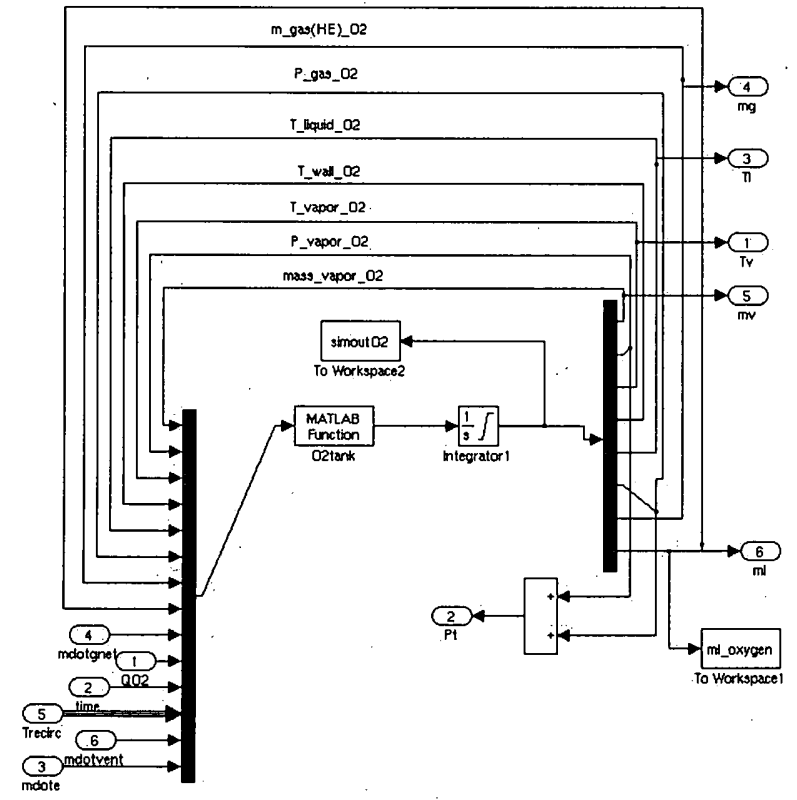

(a) Oxygen

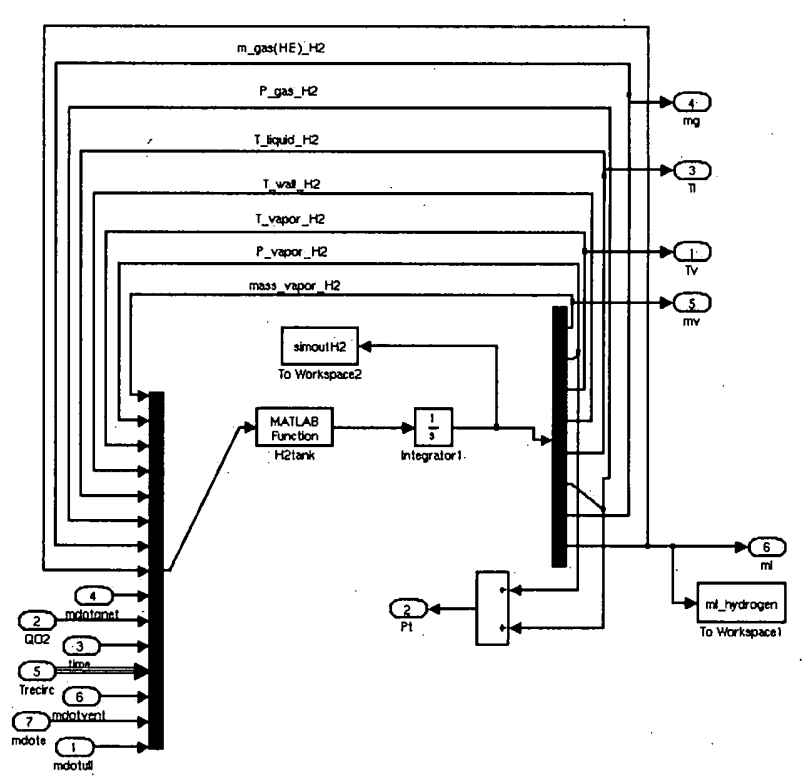

(b) Hydrogen

Figure 3. Fuel and Oxidizer tank models

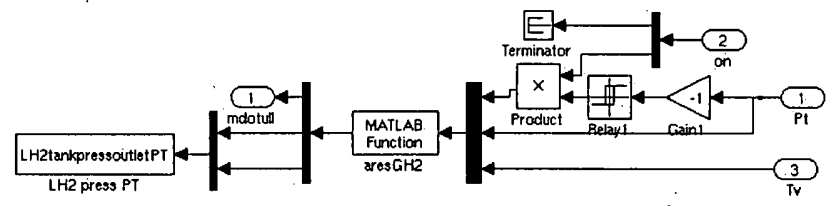

Figure 4. Hydrogen ullage regulation block for fuel expulsion mode

\section{III.D. Recirculation Loop}

For recirculation modeling, the parts of the $\mathrm{J}-2 \mathrm{X}$ in contact with the fuel and oxidizer streams are modeled as a thermal capacitance.

$$
\dot{T}_{J 2 X}=\frac{\dot{Q}_{J 2 X}}{m_{J 2 X} c_{J 2 X}}
$$

The heat transfer rate is modeled as forced convection.

$$
\dot{Q}_{J 2 X}=h_{J 2} A_{J 2}\left(T_{l}-T_{J 2 X}\right)
$$

Fuel and oxidizer fluid warming are modeled using constant specific heat such that

$$
T_{r e}=T_{l}+\frac{T_{l}-\dot{Q}_{J 2 X}}{\dot{m}_{r e} c_{l}}
$$

The simulink implementation for the $\mathrm{O}_{2}$ and $\mathrm{H}_{2}$ sides are identical except for fluid properties (including mass flow rates). Thus we show only the $\mathrm{O}_{2}$ half. Area $A_{J 2}$, and heat transfer coefficient $h_{J 2}$ are external constants for trade studies and further refinement.

\section{III.E. Prevalve and Recirculation Isolation Valve}

The prevalves and recirculation isolation valves are simulated by simple time driven relays, and gains. Sensors for both open and closed positions are simulated by a boolean not. Flow rates are determined by a gain. Apart from flow rate gains, the $\mathrm{O}_{2}$ implementations are identical to those shown below for $\mathrm{H}_{2}$. 


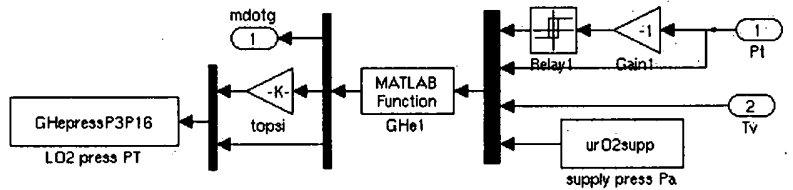

(a) Oxygen

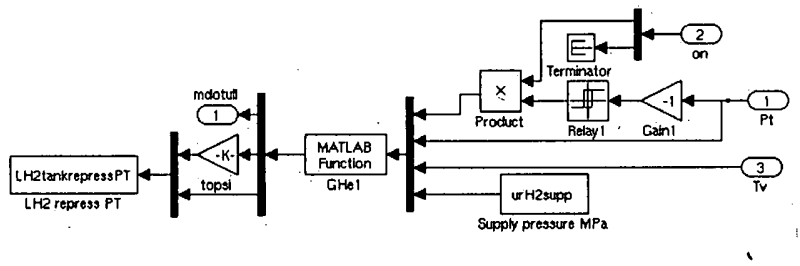

(b) Hydrogen

Figure 5. Ullage regulation blocks for gaseous He injection

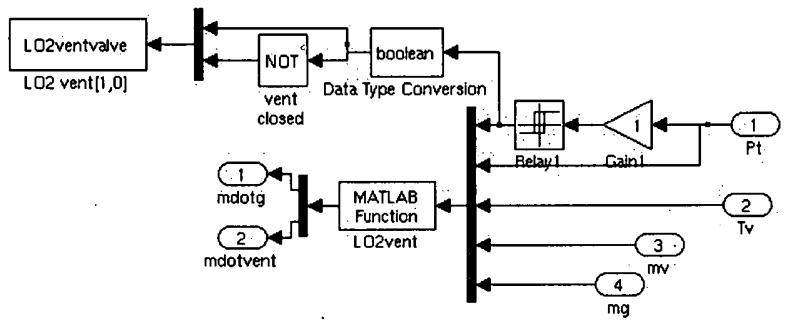

(a) Oxygen

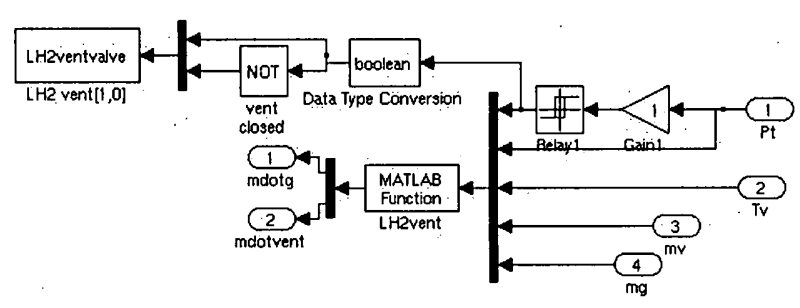

(b) Hydrogen

Figure 6. Relief Vent blocks for $\mathrm{O}_{2}$ and $\mathrm{H}_{2}$ tanks

\section{III.F. Liquid Level Floats}

The liquid level sensors are implemented directly from the liquid propellant / oxidizer mass remaining in the tank as shown below. Floats are simulated for overfill, $100 \%$ plus, $100 \%, 100 \%$ minus, $98 \%, 5 \%$, and low level. The $\mathrm{O}_{2}$ implementation is identical to that shown, with a different gain to reflect tank capacity.

\section{III.G. Tank Bottom Pressure}

Current vehicle acceleration is imported from a Maveric simulation of a nominal vehicle trajectory. Tank bottom pressure is determined by finding the liquid height in the tank, then multiplying by the fluid density, and current vehicle $x$ axis acceleration. This value for fluid column head is then added to the ullage pressure. The liquid height in the $\mathrm{O}_{2}$ tank is calculated by numerically solving Eqn 55 for $h$. The $\mathrm{H}_{2}$ liquid height is calculated using a cylindrical tank model.

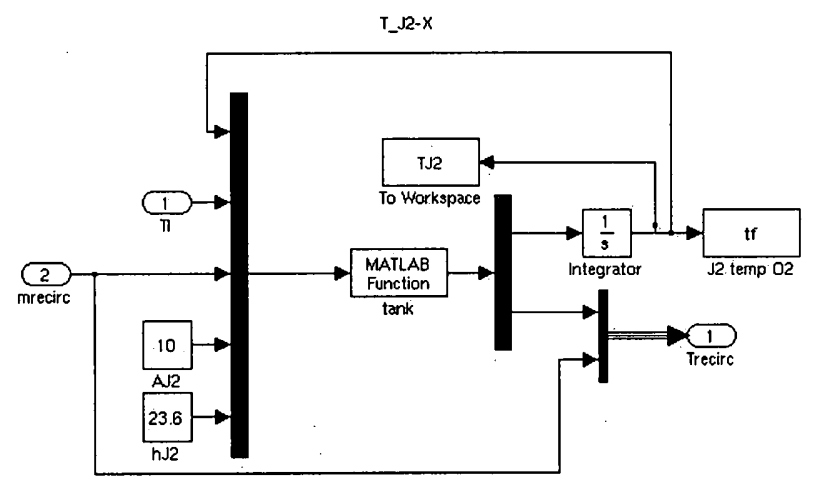

Figure 7. Simulink implementation of the recirculation loop 


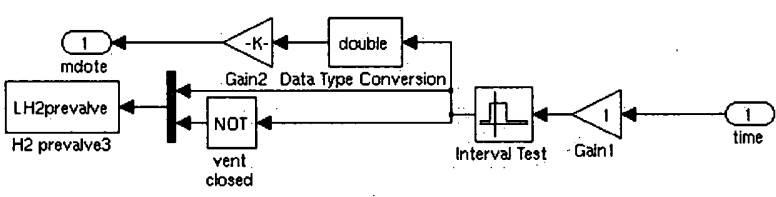

(a) Prevalve

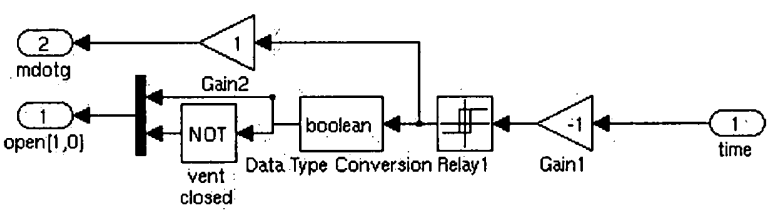

(b) Recirculation Isolation

Figure 8. Prevalve and Recirculation Isolation valve simulation blocks

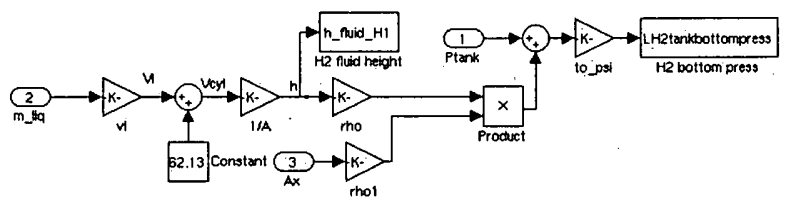

(a) Hydrogen

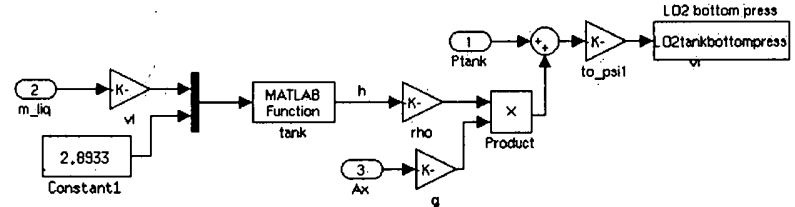

(b) Oxygen

Figure 9. Tank bottom pressure sensor simulation blocks

\section{III.H. Cryogenic Helium Supply pressure}

The current value of cryogenic He pressure is computed by GASP from current density and $\mathrm{H}_{2}$ vapor temperature. The mass remaning in the cryo He tanks is found by integrating the net mass flow rates through the ullage regulators. The mass remaining is then divided by the total tank volume to find density. Here we show the simulink implementation.

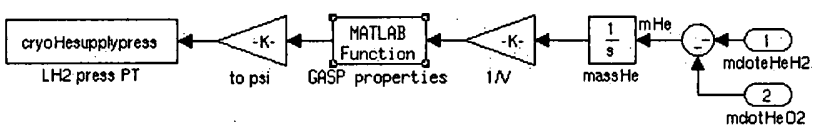

Figure 10. Simulink model of cryogenic He tank pressure

\section{Simulation Results}

\section{IV.A. Validation}

The basic function of our model was compared to an equivalent model in GFSSP ${ }^{6}$ to show the validity of our model. Although the fundamental physics modeled in the two systems are essential the same, there are some major differences in the numerical schemes involved. Most significantly, GFSSP uses an upwind finite differencing scheme such that the time marching equations are reduced to algebraic equations whose solution has accuracy similar to an Euler integration scheme. Both methods are currently using the GASP package for fluid properties which ensures a high degree of accuracy. Calculation of fluid to ullage and ullage to wall heat transfer coefficients were identical between the two methods. Other heat transfer coefficients are not well documented for GFSSP.

Several factors influence the frequency of ullage repressurization oscillations perceived as the 'sawtooth' pattern of pressure response. The most significant at any time is the ullage volume. We adjusted the ullage volume in our simulation to roughly match the GFSSP response. Subsequent tuning was performed by choosing heat transfer coefficients from outside air to tank wall and tank wall to liquid propellant / oxidizer as adjustable parameters. These free variables were then tuned so that the simulink model pressure response matched the GFSSP response best in a least squares sense. The results are shown above. The time axes are zoomed above to aid in comparison.

The validation results are promising. Although the oscillations eventually move out of phase with GFSSP, 


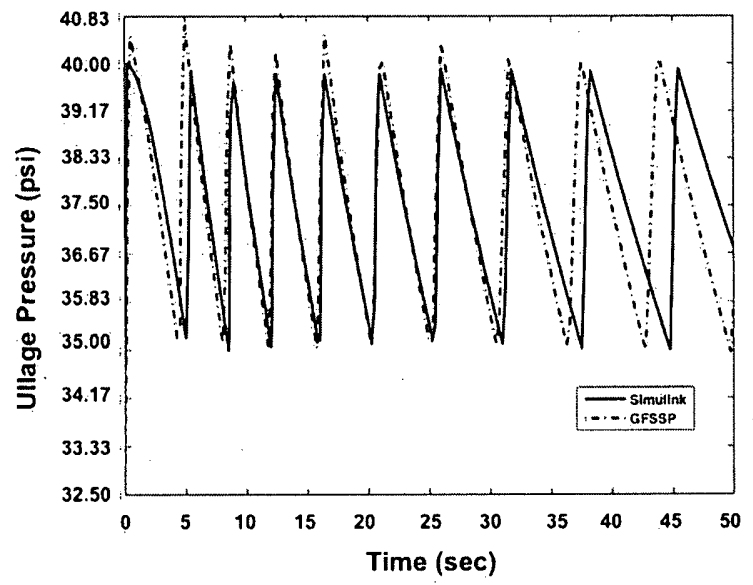

(a) Hydrogen Tank

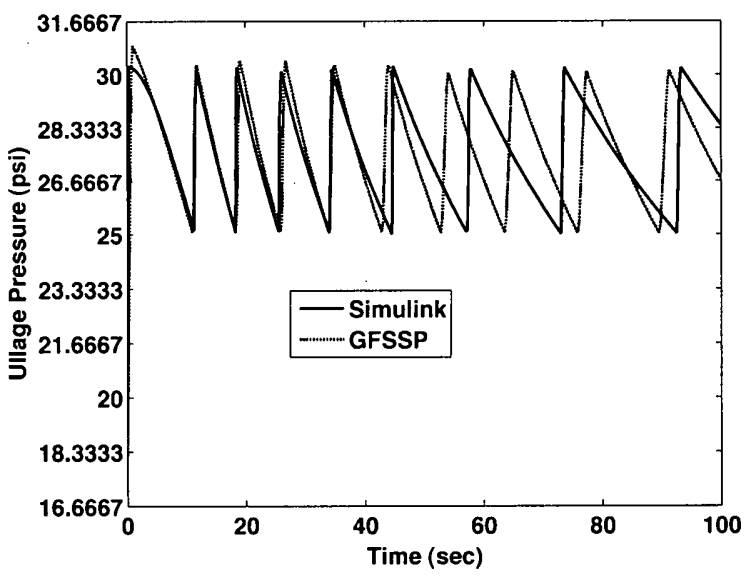

(b) Oxygen Tank

Figure 11. Validation using GFSSP

note that the upward and downward slopes are quite comparable. The largest differences are caused by the GFSSP pressurization valve remaning open too long. Simulink automatically adjusts the simulation time step to precisely capture discrete changes such as valve openings / closings. GFSSP instead requires that the valve opens over a finite time interval, and does not check solution accuracy on the fly.

\section{IV.B. Detailed Results}

Figures 12 and 13 display simulation results for first stage boost (re-pressurization) and second stage firing (pressurization). Each pressure plot shows the partial pressure of ullage gas species, total ullage pressure and tank bottom pressure. Tank bottom pressure is essential to maintaining net positive suction head, and is restricted by structural limits. Each tank experiences a step in ullage pressure at the beginning of the simulation. First stage vehicle acceleration has an obvious effect on tank bottom pressure.

The temperature plots show vapor temperature, liquid temperature and film temperature. It is important to remember that the film is modeled as an infinitessimal control volume, and thus film temp is assumed to be the saturation temperature at current ullage pressure.

Ullage gas mass illustrates the key difference in Oxygen and Hydrogen tanks. Hydrogen vapor is injected into the Hydrogen tank to maintain ullage pressure during mainstage. Helium is injected into the Oxygen tank.

Given that our results are comparable to those from GFSSP, we favor the use of Simulink in further development for the following reasons.

1. Numerical Robustness: GFSSP's numerical solution can have stability problems if the initial conditions (especially temperatures) are not set carefully. Simulink has built-in adjustable step algorithms that ensure accuracy of the solution.

2. (Ex) portability: In GFSSP, the equations are hidden to the user. It serves as a good tool to create predictions, but would require extra effort to port the actual equations to another application say a fault detection algorithm

3. Ease of adding features (and faults): GFSSP provides the flexibility to add new features like heat transfer to solids, but before long the user must write and compile FORTRAN subroutines to implement these features. In Simulink additional valves and logic are easily implemented by adding relays or interval tests. Faults may be introduced in many cases by introducing erroneous limits on switches.

GFSSP does account for the difference in temperature between added ullage gas and fuel / oxidizer vapor. We found the volume and rate of cooling of ullage gas to be the most influential factors in the frequency of ullage pressure oscillations. Adjusting these factors in GFSSP to match the simplifying assumptions in our simulation caused the quality of agreement shown above. 


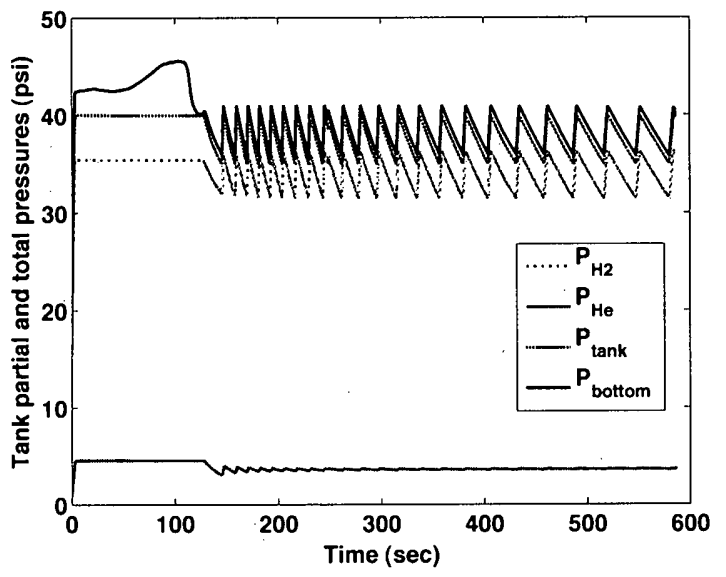

(a) Pressure

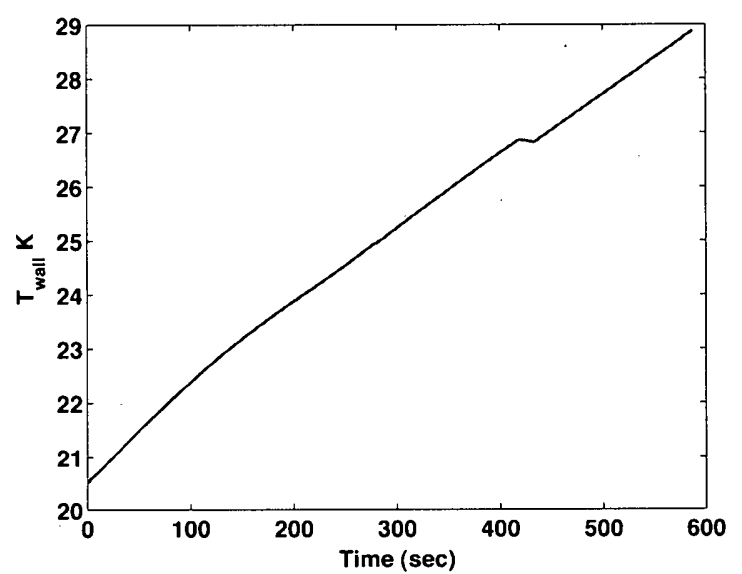

(c) Wall Temperature

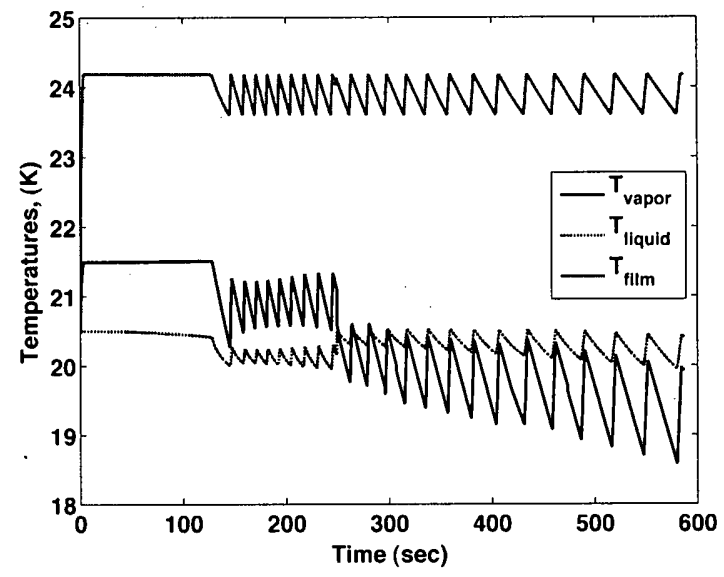

(b) Temperature

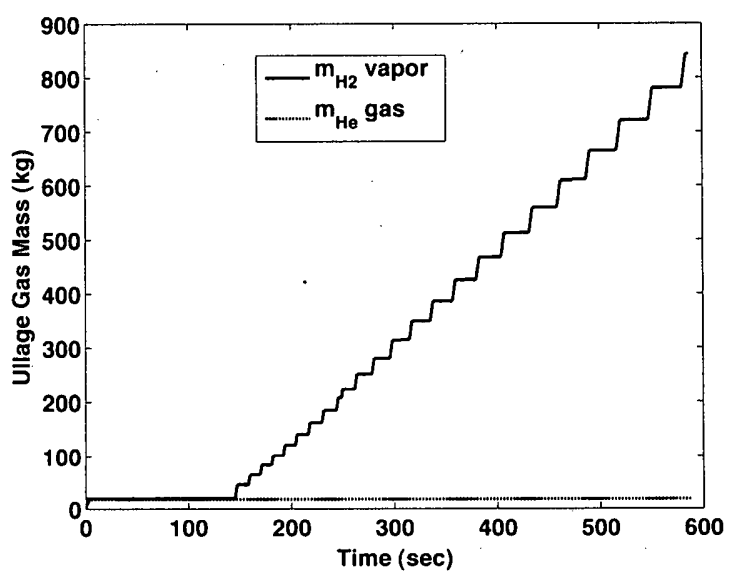

(d) Ullage Mass

Figure 12. Simulation results for Liquid Hydrogen tank 


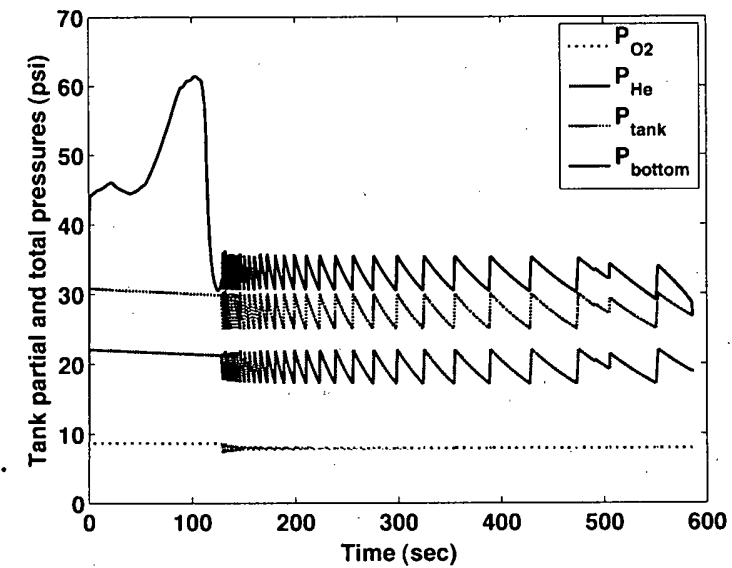

(a) Pressure

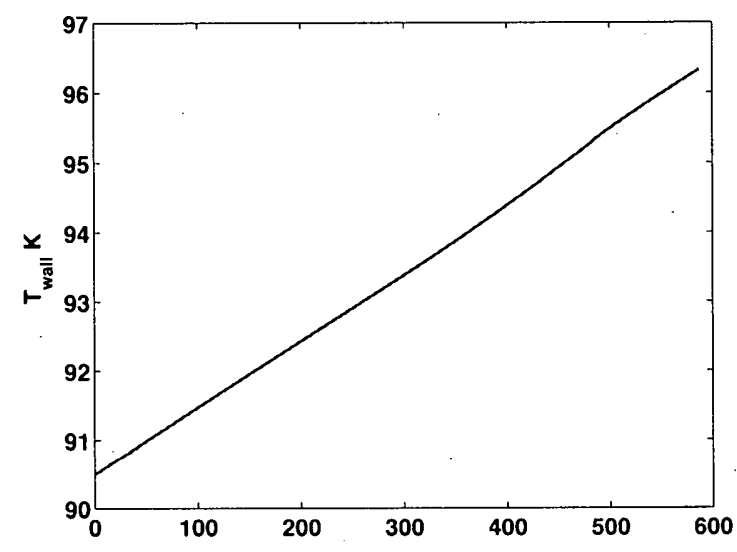

(c) Wall Temperature

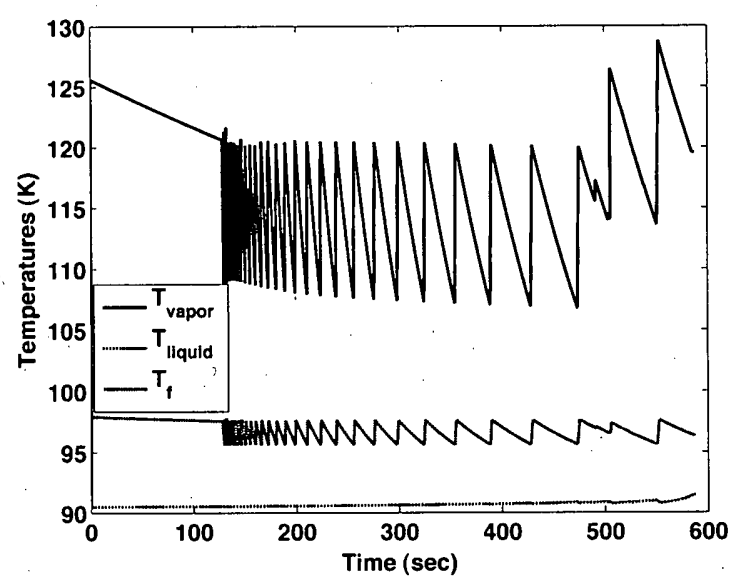

(b) Temperature

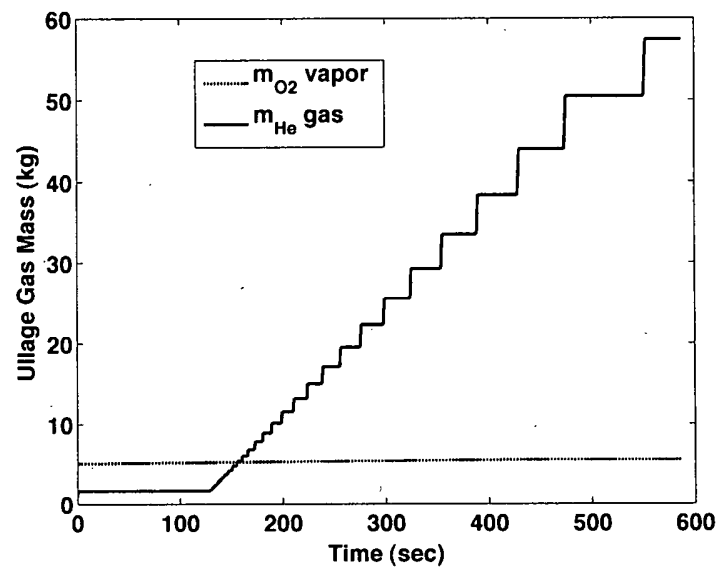

(d) Ullage Mass

Figure 13. Simulation results for Liquid Oxygen tank 


\section{Conclusions}

A simulink model of major components of the Ares I upper stage main propulsion system has been developed. Equations are based on conservation of energy for a small number of control volumes, and constraints from an isothermal ullage gas assumption, and invariant total tank volume. Thermophysical and transport properties of the working fluids are computed using the GASP ${ }^{16}$ package which has been 'mex-ed' for use with Matalb / Simulink. Tank pressurization results during fuel / oxidizer expulsion are comparable to results from an established resource. This model, still under development has the potential to provide realistic nominal and fault simulation of sensors critical to an abort decision on the Ares I.

\section{Acknowledgments}

The author gratefully acknowledges the NASA / Marshall Space Flight Center Academic Affairs Office funded Universities Space Research Association Visiting Researcher and Exchange Program for their sponsorship. Also many thanks to Mike Watson and Jon Patterson of MSFC Integrated Systems Health Management and Sensors Branch for their support.

\section{References} 1965.

${ }^{1}$ Roudebush, W. Wh., "An Analysis of the Problem of Tank Pressurization During Outflow," NASA TN D-2585, Jan.

${ }^{2}$ Pasley, G. F., "Optimization of Stored Pressurant Supply for Liquid Propulsion Systems," Journal of Spacecraft and Rockets, Vol. 7, Dec. 1970, pp. 1478-1480.

${ }^{3}$ Kendle, D. W., "Ullage Mixing Effects on Tank Pressurization Performance," Journal of Spacecraft and Rockets, Vol. 8, No. 9, pp. 990-992, Sept. 1971

${ }^{4}$ Bush, W. B., Fendell, F. E., and Muirhead, L. P., "Pressure Rise in a Liquid Fuel Tank Owing to Volumetric Heating," Journal of Thermophysics, Vol. 3, No. 2, pp. 140-145, April, 1989.

${ }^{5}$ McDonald, J. P., Minor, R. B., Knight, K. C., Champion, R. H., and Russell, F. J., "Propellant Feed Subsystem for the X-34 Main Propulsion System," AIAA 98-3517.

${ }^{6}$ Majumdar, A., and Steadman, T., "Numerical Modeling of Pressurization of a Propellant Tank," Journal of Propulsion and Power, Vol. 17, No. 2, pp. 385-390, March-April, 2001.

${ }^{7}$ Holt, K., Majumdar, A., Steadman, T., and Hedayat, A., "Numerical Modeling and Test Data Comparison of Propulsion Test Article Helium Pressurization System," 36th AIAA/ASME/SAE/ASEE Joint Propulsion Conference, Huntsville, AL, July 16-19, 2000.

${ }^{8}$ Hedayat, A., Knight, K. C., and Champion, R. H., "Transient Analysis of Pressurization and Pneumatic Subsystems of the X-34 Main Propulsion System," 36th AIAA/ASME/SAE/ASEE Joint Propulsion Conference, Huntsville, AL, July 16-19, 2000.

${ }^{9}$ Adnani, P., and Jennings, R. W., "Pressurization Analysis of Cryogenic Propulsion Systems," 36th AIAA/ASME/SAE/ASEE Joint Propulsion Conference, Huntsville, AL, July 16-19, 2000.

${ }^{10}$ Hearn, H. C., "Development and Validation of Fluid/Thermodynamic Models for Spacecraft Propulsion Systems," Journal of Propulsion and Power,' Vol. 17, No. 3, pp. 527-533, May-June, 2001.

${ }^{11}$ Zilliac, G., and Karabeyoglu, M. A., "Modeling of Propellant Tank Pressurization," 41st AIAA/ASME/SAE/ASEE Joint Propulsion Conference, Tucson, AZ, July 10-13, 2005.

${ }^{12}$ Estey, P. N., Lewis, D. H., and Connor, M., "Prediction of a Propellant Tank Pressure History Using State Space Methods," Journal of Spacecraft and Rockets, Vol. 20, No. 1, pp. 49-54, Jan-Feb, 1983.

${ }^{13}$ Palm, W. J., Modeling, Analysis, and Control of Dynamic Systems, 2nd ed., John Wiley and Sons, New York, 2000.

${ }^{14}$ White, F. M., Fluid Mechanics, 3rd ed., McGraw-Hill, New York, 1994.

${ }^{15}$ Ring, E., Rocket Propellant and Pressurization Systems, Prentice Hall, Englewood Cliffs, N. J., 1964.

${ }^{16}$ Hendricks, R. C., Baron, A. K., and Peller, I. C., "GASP-A Computer Code for Cailculating the Thermodynamic and Transport Properties for ten Fluids," TN D-7808, Feb. 1975, NASA.

${ }^{17}$ NIST Chemistry WebBook, http://webbok.nist.gov/chemistry/, accessed July 12, 2007.

${ }^{18} \mathrm{http}: / /$ www.nasaspaceflight.com/content/?cid=5013, accessed July 12, 2007. 


\section{Appendix}

Here is the entire Simulink model

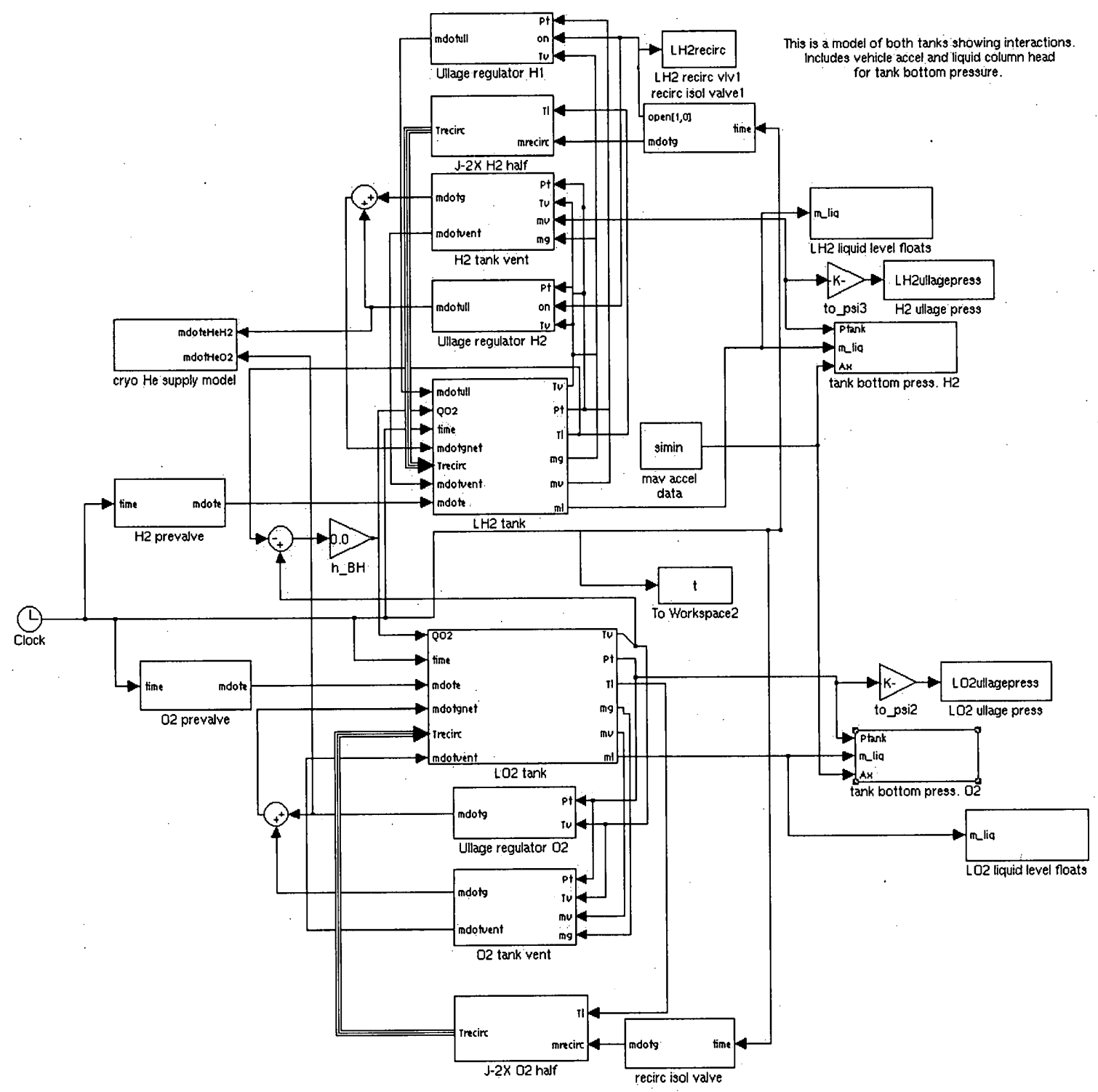

Figure 14. Simulink top-level block diagram 


\section{Subject: RE: Export control / ITAR question}

Date: Monday, November 5, 2007 11:28 AM

From: Nelson, Michael A. (MSFC-ER21) <Michael.A.Nelson@nasa.gov>

To: "Burchett, Bradley T. (MSFC)[]" <bradley.t.burchett@nasa.gov>

Conversation: Export control / ITAR question

Hey Brad,

Absolute numbers are not allowed to go out on the ARES. The equations are generally available from already available public documents. So it is fine to show all the equations and relationships as you have done. It is just the absolute numbers about ARES that can not be made publicly available.

So take the absolute numbers out and try to maybe show "example" ranges of numbers to get your point across without giving away the absolute numbers. You could zero out the bottom of a range and instead of going from 6 to 40 it goes from 0 to 34 or something of that nature. or you could-multiply, everything, by some unpublished amount and make a note to the effect that the numbers shown are not actual ARES numbers but have- h been modified to avoid release of ARES design details to the public per ITAR restriztions.

Hope this helps.

Michael

----original Message-----

From: Burchett, Bradley T. (MSFC) []

Sent: Monday, November 05, 2007 11:16 AM

To: Nelson, Michael A. (MSFC-ER21)

subject: Export control / ITAR question

Mike,

I am hoping to present the attached paper at the 2008 AIAA MST conference.

Mike Watson asked that I confer with you regarding how ITAR might apply to the attached paper. The paper currently includes some numbers such as ullage pressures specific to Ares I. Where do we draw the line? would it be okay as is, or should I remove the numbers specific to Ares? Are there other design details that need to be deleted as well (references to $\mathrm{J} 2 \mathrm{X}$, etc)?

Thanks for any help you can provide, Brad

Bradley T. Burchett, Ph.D., P.E.

Associate Professor

bradley.t.burchett@nasa.gov

NASA VREO fellow, MSFC EV-43, Jun - Dec 2007

"Force necessarily implies a mind. Thought moves mind and mind moves things. Force is the product of mind. None can, therefore, assert the reign of 'law' or 'force' without demonstrating the existence of the personal God of the Bible, which is the fact he seeks to deny...A process, necessarily implies contrivance, marks of design, and an intelligent Designer, which is God. Since a process cannot be the 